\title{
Syntactic priming in comprehension: Parallelism effects with and without coordination
}

\author{
Patrick Sturt \\ Department of Psychology, School of Philosophy, Psychology \\ and Language Sciences, University of Edinburgh \\ 7 George Square, Edinburgh EH8 9JZ, UK \\ patrick.sturteed.ac.uk \\ Frank Keller and Amit Dubey \\ School of Informatics, University of Edinburgh \\ 10 Crichton Street, Edinburgh EH8 9AB, UK \\ \{frank.keller, amit.dubey\}@ed.ac.uk
}

\begin{abstract}
Although previous research has shown a processing facilitation for conjoined phrases that share the same structure, it is currently not clear whether this parallelism advantage is specific to particular syntactic environments such as coordination, or whether it is an example of more general effect in sentence comprehension. Here, we report three eye-tracking experiments that test for parallelism effects both in coordinated noun phrases and in subordinate clauses. The first experiment replicated previous findings, showing that the second conjunct of a coordinated noun phrase was read more quickly when it had the same structure as the first conjunct, compared with when it did not. Experiment 2 examined parallelism effects in noun phrases that were not linked by coordination. Again, a reading time advantage was found when the second noun phrase had the same structure as the first. Experiment 3 compared parallelism effects in coordinated and non-coordinated syntactic environments. The parallelism effect was replicated for both environments, and was statistically equivalent whether or not coordination was involved. This demonstrated that parallelism effects can be found outside the environment of coordination, suggesting a general syntactic priming mechanism as the underlying explanation.
\end{abstract}

\section{Keywords: Sentence Processing; Parallelism; Priming; Eye-tracking}

\section{Introduction}

It has been repeatedly observed that the processing of a linguistic unit is facilitated by the recent processing of a linguistic unit with an equivalent syntactic form (see Pickering \& Ferreira, 
2008 , for a review). Such syntactic priming effects are particularly well-attested in language production, where there is a tendency for speakers (or writers) to re-use syntactic forms that they have recently produced. Priming effects have been found not only in experimental investigations (e.g., Bock, 1986; Pickering \& Branigan, 1998; Scheepers, 2003), but also in corpus studies of spontaneous speech (Reitter, Moore, \& Keller, 2006; Reitter, Hockenmaier, \& Keller, 2006) and written language (Szmrecsanyi, 2005; Gries, 2005; Dubey, Keller, \& Sturt, 2008). The probability of producing a particular syntactic form is affected not only by the speaker's own prior production of that form, but also by his or her comprehension of another person's use of that form, as has been shown experimentally by Branigan, Pickering, and Cleland (2000).

In contrast to the considerable evidence for syntactic priming in production, there have been relatively few studies investigating priming effects in comprehension. However, a number of recent studies have shown that the comprehension of a syntactic form is indeed facilitated by the recent exposure to a similar syntactic form, and there are a number of ways in which syntactic priming can affect the comprehension of a subsequent target stimulus. Priming can ease the recovery from syntactic garden paths (Branigan, Pickering, Liversedge, Stewart, \& Urbach, 1995; Ledoux, Traxler, \& Swaab, 2007; Traxler, 2008); it can also affect the final interpretation of a globally ambiguous sentence (Branigan, Pickering, \& McLean, 2005); and it can modulate expectation levels for upcoming constituents, as measured by eye-movements during scene viewing (Arai, Gompel, \& Scheepers, 2007; Thothathiri \& Snedeker, 2008).

In the present paper, we will consider a phenomenon that appears to share many characteristics with syntactic priming, viz., the parallelism preference in the interpretation of coordinated structures. This effect was first reported by Frazier, Taft, Roeper, Clifton, and Ehrlich (1984), and has been confirmed in a series of recent studies (Frazier, Munn, \& Clifton, 2000; Carlson, 2001; Knöferle \& Crocker, 2009). It is well-known that, with certain exceptions, the coordination of two constituents requires each conjunct to have the same syntactic category (Chomsky, 1957). In addition to this, it can be shown that the processing of the second conjunct is facilitated if it has the same the internal structure as the first conjunct. For example, Frazier et al. (2000) examined sentences like (1) in an eye-tracking study:

(1) a. Hilda noticed a strange man and a tall woman when she entered the house.

b. Hilda noticed a man and a tall woman when she entered the house.

c. Hilda noticed a strange man and a woman with a dog when she entered the house.

d. Hilda noticed a man and a woman with a dog when she entered the house.

They found that on the second conjunct (underlined in (1)) total times were longer in (1b) than in (1a), while (1c) and (1d) did not differ. This finding was attributed to the fact that the two conjuncts in (1a) share the same internal structure (determiner, adjective, noun), while those in (1b) do not. The conditions (1c) and (1d) control for the possibility that any difference between (1a) and (1b) might be attributable to priming based on the presence or absence of a modifier. Since both conjuncts include a modifier in (1c) but not in (1d), such an account would predict a facilitation

\footnotetext{
We thank Frances Wilson for data collection. Portions of this work were presented at the AMLaP conferences in 2007 and 2008. We thank the audiences of these conferences for their comments. This work benefited from discussions with Matthew Crocker and Pia Knöferle, as well as from the comments of three reviewers. The research was supported by Leverhulme Trust grant number F/00 158/AL and ESRC grant number RES-062-23-1450.
} 
for (1c) relative to (1d). The lack of such an effect led the authors to conclude that the difference between (1a) and (1b) was due to the parallelism of syntactic form.

If we view the first conjunct as a prime and the second conjunct as a target, then this parallelism effect has obvious similarities with syntactic priming. However, Frazier et al. (2000) argued that the effect is the result of a phenomenon separate from general syntactic priming, as syntactic priming should be observable across the board in different syntactic environments, whereas Frazier et al. (2000) found facilitation for parallel structures only when the structures were coordinated. In a subsequent experiment using segment-by-segment self-paced reading, Frazier et al. (2000) examined sentences such as (2), in which the two critical noun phrases were not in a coordinate context, but instead were the subject and object of a verb.

(2) a. A strange man noticed a tall woman yesterday at Judi's.

b. A man noticed a tall woman yesterday at Judi's.

c. A strange man noticed a woman yesterday at Judi's.

d. A man noticed a woman yesterday at Judi's.

Frazier et al. (2000) found no evidence for parallelism in the reading times for the underlined segment in (2). This led them to conclude that the facilitation that they had previously observed for (1) was not due to general syntactic priming, but was attributable to a specialized parallelism effect that is limited to certain syntactic contexts such as coordination environments.

In this paper, we will address the question of whether the parallelism effect is indeed limited to coordination, or whether it can be found in other syntactic environments as well. In particular, we will present evidence that suggests that parallelism effects for noun phrases related by subordination are similar to those found for coordination, a result that is compatible with an explanation of parallelism as a priming effect. If the priming view is correct, then this would simplify accounts of sentence processing considerably; a priming mechanism is independently motivated, and being able to explain a seemingly distinct effect such as parallelism as priming would lead to a more elegant, more parsimonious theory. The question of whether parallelism is priming is therefore of considerable theoretical importance.

The claim that parallelism effects are a consequence of priming is consistent with a recent model proposed by Dubey et al. (2008), which is based on probabilistic context free grammars (PCFGs). In this model, the probability of a rule is conditioned on whether or not that rule has been used before in a given context (e.g., the whole sentence or the previous sentence). This leads to a higher probability for a rule that has been primed, relative to a rule that is not re-used. This contrasts with standard PCFGs which assume that the probability of a rule in a derivation is independent of all the other rules in that derivation. Dubey et al. (2008) use surprisal (Hale, 2001) as a linking hypothesis to map model probabilities onto experimentally obtained reading times. Surprisal predicts that the difficulty of processing a word $w$ is a function of the probability of $w$ given the words that precede $w$; the lower this probability, the higher the processing cost, and hence the higher the predicted reading time. Dubey et al. (2008) show that a PCFG-based model that is augmented with a priming-based "boost" in its probability model successfully predicts the pattern of processing cost observed in parallelism experiments, including those of Frazier et al. (2000) and Knöferle and Crocker (2006). This type of mechanism is similar in many ways to the the activation of combinatorial nodes in descriptive accounts of priming in production (e.g., Pickering \& Branigan, 1998). Combinatorial nodes can be seen as equivalent to context-free phrase structure rules, and the relative activation (rather than probabilities) of the relevant nodes determines the strength of preference for 
one structural form over another.

Although Frazier et al. (2000) argued that parallelism effects are distinct from priming, there are reasons why this conclusion might be premature. First, it should be noted that their conclusion is based on a comparison between two experiments using different methods. The parallelism effect was obtained for (1) using eye-tracking, while a null effect was obtained for the stimuli in (2) using self-paced reading, a method which is usually considered less sensitive than eye-tracking. ${ }^{1}$ Moreover, self-paced reading does not allow the reader to re-inspect earlier parts of the sentence. However, the possibility to make such re-inspections may have been crucial to finding a parallelism effect, since Frazier et al.'s (2000) eye-tracking study showed the effect only in total times (which include re-inspections) but not in first-pass reading times (which do not).

A more recent study reported by Apel, Knoeferle, and Crocker (2007) addressed some of these issues by using the same method, namely eye-tracking, to examine parallelism effects in both coordinate and non-coordinate contexts. In their Experiment 1, they examined parallelism in coordination, using stimuli similar to (3):

(3) a. Der Esel und der melkende Bauer sind vor dem Gewitter geflüchtet.

(The donkey and the milking farmer escaped from the thunderstorm.)

b. Der dämliche Esel und der melkende Bauer sind vor dem Gewitter geflüchtet.

(The dimwitted donkey and the milking farmer escaped from the thunderstorm.)

c. Der stampfende Esel und der melkende Bauer sind vor dem Gewitter geflüchtet.

(The stamping donkey and the milking farmer escaped from the thunderstorm.)

In all conditions, the second noun phrase conjunct consisted of a determiner followed by a participle (e.g., melkende (milking)) followed by a noun. The experimental design manipulated the form of the first conjunct, which was either parallel syntactic form (as in (3c), including a pre-modifying participle), or non-parallel (as in (3a), including no modifier, or (3b), including an adjective instead of a participle). Regression path times were measured on the head noun of the second NP conjunct (underlined in (3)). It was found that regression path times were faster in the parallel condition (3c) relative to the other two conditions.

In their second experiment, Apel et al. (2007) tested the same noun phrases in a noncoordinating syntactic context. Instead of appearing as conjuncts, the first and the second NPs appeared as the subject and the object of a main verb, as in (4):

(4) a. Der Esel beißt den melkenden Bauern ohne jede Vorwarnung.

(The donkey bites the milking farmer without any warning.)

b. Der dämliche Esel beißt den melkenden Bauern ohne jede Vorwarnung.

(The dimwitted donkey bites the milking farmer without any warning.)

c. Der stampfende Esel beißt den melkenden Bauern ohne jede Vorwarnung.

(The stamping donkey bites the milking farmer without any warning.)

In this experiment, Apel et al. (2007) did not observe any significant effects at the head noun, in contrast to the results of the first experiment. This led them to concur with Frazier et al. (2000) that parallelism effects are not due to general syntactic priming, but they are restricted to certain syntactic contexts, such as coordination.

\footnotetext{
${ }^{1}$ While this is true in terms of resolution, self-paced reading could show effects that do not come into play fast enough in eye-tracking, as one of the reviewers points out.
} 
However, there are other potential reasons for the lack of a parallelism effect in the noncoordinating contexts investigated by Frazier et al. (2000) and Apel et al. (2007). One of these is that, in their non-coordinating experiments, both sets of authors arranged the stimuli so that the first noun phrase was the subject of a transitive verb and the second noun phrase was its object. This means that the two NPs differed in grammatical function in the non-coordinating contexts (one was a subject and the other an object) while they had the same grammatical function in the coordinating contexts (both were subjects). The fact that NPs are case marked in German makes this difference more prominent in Apel et al.'s (2007) experiment: In (4), the supposedly parallel NPs differ in both in grammatical function and in case-marking (der stampfende Esel (the stamping donkey) is nominative marked, while den melkenden Bauern (the milking farmer) is accusative marked). It is possible that parallelism in grammatical function and case marking is required for an overall syntactic parallelism effect, or that the parallelism effect is weaker if grammatical function is not parallel, making it more difficult to detect (note that both Frazier et al. (2000) and Apel et al. (2007) base their claims on null effects in their non-coordinating experiments).

A more general point is that the experimental manipulations used by Frazier et al. (2000) and Apel et al. (2007) manipulate not only syntactic form, but also semantics. An NP with an adjective or PP modifier has a meaning that is different from (more restricted than) that of an NP without a modifier, and the meaning of an NP may differ depending on the type of modifier (adjective, participial or PP). It is possible that these differences in meaning contributed to any effects that were observed. This contrasts with classical syntactic priming studies in the production literature, which have used alternative sentence forms that are as close as possible in meaning. Examples include active and passive, or ditransitive verbs that can occur with either a double object or a prepositional object. These syntactic alternatives either do not differ in truth-conditional semantics or differ only minimally, so any priming effects observed can be attributed to a repetition in syntactic form alone.

The evidence reviewed above is therefore inconclusive with respect to the extent to which the parallelism preference is the result of specialized processes that occur in coordination and related syntactic environments. In this paper, we argue for an alternative view in which the parallelism effect is an instance of a more general syntactic priming effect in comprehension. We present a series of experiments that eliminate the confounds in the Frazier et al. (2000) and Apel et al. (2007) studies discussed above. Our experiments compare syntactic structures that are truth-conditionally equivalent (thus eliminating the semantic confound) and compare coordinate contexts to subordinate contexts (thus eliminating the confound with grammatical function, as explained below). We test (in Experiment 3) coordinate and non-coordinate structures in the same experiment, thus eliminating the problem of having to compare across experiments, and the need to argue on the basis of a null effect. Our results provide evidence for parallelism effects outside coordination, once these confounding factors are controlled. This finding makes it possible to accommodate syntactic parallelism in a general model of syntactic priming in comprehension, such as the one proposed by Dubey et al. (2008), as described above. This obviates the need for a specialized mechanism that only applies to coordinate structures, yielding a more parsimonious account overall.

This paper is organized as follows. Experiment 1 replicates the parallelism effect in coordination for syntactic constructions that are truth-conditionally equivalent. Experiment 2 extends this by testing for parallelism effects in non-coordinate structures, viz., subordinate clauses. Experiment 3 replicates these results and compares coordinate and subordinate structures in a single experiment. This is followed by a General Discussion of the implications of our results. 


\section{Experiment 1}

The aim of this experiment was to replicate the parallelism effect observed by Frazier et al. (2000). To avoid the semantic confound mentioned in the introduction, this replication used a syntactic alternation that keeps the truth conditional semantics of the two constructions as close to being constant as practically possible. This involved using noun phrases which were either premodified by an adjectival phrase (e.g. a difficult to read book) or postmodified by a relative clause (e.g. a book that was difficult to read). ${ }^{2}$

The modifiers used in this experiment used the tough construction (e.g. difficult to read). In general, multi-word adnominal premodifiers are 'marked' in English. That is to say, they have reduced acceptability presumably due to their low frequency. This may be a desirable feature in the context of syntactic priming studies: previous studies (Scheepers, 2003) have demonstrated that the magnitude of the priming effect is inversely proportional to the relative markedness of the structure (where the relative markedness corresponds to the baseline preference for this structure in the absence of a prime). If we assume that these results carry over to syntactic parallelism in comprehension, then incorporating a marked construction could increase the size of the priming effect, thus making it easier to detect.

\section{Method}

Participants. Twenty-eight native speakers of English from the University of Edinburgh community were paid to participate in the experiment.

Stimuli. Twenty-four experimental items were constructed (see Appendix for a full list), each of which began with a coordinated subject noun phrase. The experimental design orthogonally manipulated the syntactic form of the two conjuncts within the subject. Each conjunct contained the tough construction, either in a post-modifying relative clause position or in the semantically equivalent but more marked pre-modifying adjectival position. Thus the two factors in the design were NP1 form (Relative Clause vs. Adjective Phrase) and NP2 form (also Relative Clause vs. Adjective Phrase). The relative clause always employed the third person past form of the copula (was), thus eliminating the possibility of the relative clause to modify the larger conjoined NP instead of the intended second conjunct. A set of example stimuli is given in (5):

a. $\quad N P 1=$ Adjective Phrase $($ AdjP $) ; N P 2=$ Adjective Phrase $($ AdjP $)$

A difficult to read book and a risky to cross street were mentioned by John's friend.

b. $\quad N P 1=$ Relative Clause $($ RelCl); $N P 2=$ Adjective Phrase $($ AdjP $)$

A book that was difficult to read and a risky to cross street were mentioned by John's friend.

c. $\quad N P 1=$ Adjective Phrase $($ AdjP $) ; N P 2=$ Relative Clause $($ RelCl $)$

A difficult to read book and a street that was risky to cross were mentioned by John's friend.

d. $\quad N P 1=$ Relative Clause $($ RelCl); $N P 2=$ Relative Clause (RelCl)

A book that was difficult to read and a street that was risky to cross were mentioned by John's friend.

\footnotetext{
${ }^{2}$ This type of semantically neutral manipulation is similar to that used by Knöferle and Crocker (2009), who manipulate the order of arguments in German verb initial clauses to investigate parallelism effects in Sentence coordination.
} 


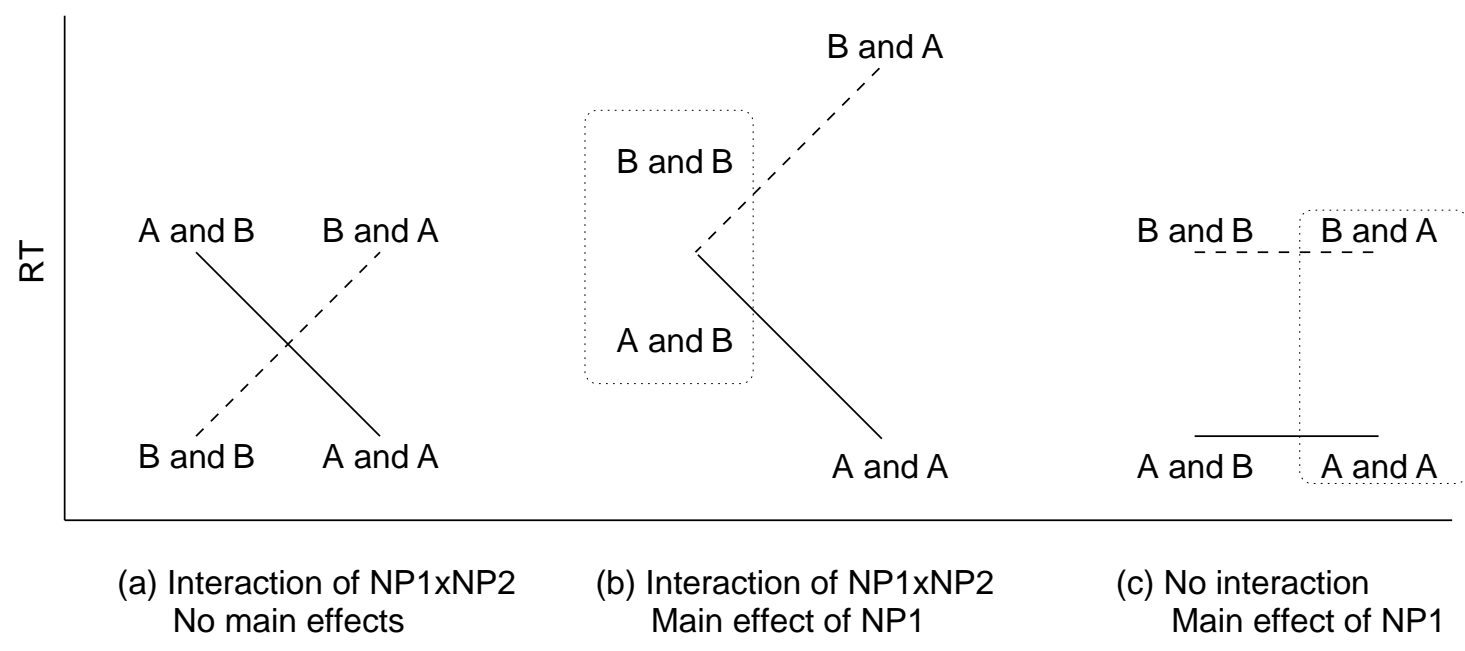

Figure 1. Three hypothetical outcomes for reading time measures on NP2 in an experimental design that crosses the form of NP1 and NP2 (form A vs. form B). The condition labels show the form of NP1 and NP2 (e.g. "A and B" means that NP1 is of form A and NP2 is of form B). Panels (a) and (b) illustrate an interaction of NP1 $\times$ NP2 consistent with a parallelism effect. The interaction, and thus the parallellism effect, is absent in panel (c). The dotted lines illustrate the danger of using non-crossed designs that only manipulate the form of NP1. The observed pattern for the two enclosed conditions could lead to a Type II error in panel (b) and a Type I error in panel (c).

The critical region for analysis was the second conjunct (underlined in (5)). Because the forms of the first and second conjuncts are fully crossed in the design, any effect of parallelism should be observable as an interaction between the two factors, such that the reading of NP2 should be relatively facilitated when preceded by an NP1 of the same syntactic form.

The crossed design has the advantage that it controls for spurious differences resulting from the processing of the first conjunct in the different conditions. For example, it is possible that one of the NP forms leads to greater spill-over difficulty in the first conjunct than the other form, affecting the main effect of type of NP1, in the critical region (NP2). If the design only manipulated the structure of NP1 without also orthogonally manipulating NP2, such differences could lead to the spurious appearance of a parallelism effect, or alternatively it might obscure a genuine parallelism effect. This crucial difference between crossed and uncrossed designs is illustrated in Figure1.

Moreover, it is not possible to make strong conclusions about differences in the magnitude of parallelism based on the form of the interaction, even when a fully crossed design is used. For example, the interaction illustrated in Figure 1, panel (b) does not necessarily mean that the magnitude of parallelism differs between the A and B forms of NP2. The apparent difference in magnitude might instead be due to the influence of the form of NP1 on reading times. Thus, although for completeness we do discuss such differences in magnitude in this paper, these differences should be interpreted with caution, and it is the overall presence of an interaction that is important for establishing a paralleism effect.

Procedure. The 96 experimental materials ( 24 items in four conditions each) were divided into four lists, such that each list contained exactly one condition of each item, and in any given list, each condition occurred the same number of times (Latin square design). Each list was combined 
with 24 fillers with varying syntactic properties. The experimental items and fillers were pseudorandomized in such a way that no two experimental items appeared adjacent to each other. The sentences were all presented on two lines. In all cases, the line break was placed immediately after the second word following the offset of the conjoined subject NP.

The experiment was run using an Eyelink II head-mounted eye-tracking system, with a sampling rate of $500 \mathrm{~Hz}$. An eye-dominance test was administered for each participant before the experiment began, and only the data from the dominant eye was included in subsequent analysis (although both eyes were tracked). The head-mounted eye-tracker was then fitted on the participant's head. A calibration procedure was carried out, and if the calibration was successful, the experiment began. Stimuli were presented with the aid of Eyetrack software developed at the University of Massachusetts at Amherst. ${ }^{3}$ Each trial began with a gaze trigger, in the form of a black square that was displayed at the left edge of the screen in a vertically central position. This square occupied the position of the start of the stimulus text, and when the participant fixated the square, it was automatically replaced by the stimulus text. When the participant had finished reading the text, he/she pressed a button on a game pad. On a quarter of the items, a yes/no question was then displayed on the screen. The participant answered the questions by pressing one of two pre-specified buttons on the game pad. If the automatic gaze contingent stimulus presentation failed on any given trial, the calibration procedure was repeated, and the trial was initiated again. The experimental trials were preceded by five practice trials.

Data Analysis. Vertical drift in the positions of fixations was corrected, using custom software developed at the University of Massachusetts (see footnote 3). An automatic procedure then pooled short contiguous fixations. The procedure incorporated fixations of less than $80 \mathrm{~ms}$ into larger fixations within one character, and then deleted any remaining fixations of less than $80 \mathrm{~ms}$. Readers do not extract much information during such short fixations (Rayner \& Pollatsek, 1989). Extremely long fixations (greater than $1200 \mathrm{~ms}$ ) were also removed.

The experimental sentences were divided into three regions. The first region consisted of all words of the sentence from the start of the sentence to the conjunction and (inclusive). The second, critical region consisted of the second NP conjunct, and is equivalent to the critical region used by Frazier et al. (2000). The final region consisted of the remainder of the sentence. Except for the first region, any given region includes the immediately preceding space. The region boundaries for an example sentence are given below:

(6) A book that was difficult to read and/ a street that was risky to cross/ were mentioned by John's friend. /

Three stimuli were removed from the analysis of the current experiment because of typographical errors.

We will report data for four eye-movement measures in the critical and final regions. First pass time consists of the sum of fixation durations beginning with the first fixation in the region until the first saccade out of the region, either to the left or to the right. Regression path time consists of the sum of fixation durations beginning with the first fixation in the region until the first saccade out of the region to the right. Note that this may include fixations to the left of the region if there is a regression before the reader moves on to the next region. Total time consists of the sum of all fixation durations in the region, regardless of when these fixations occur. Finally, second pass time

${ }^{3}$ Downloadable from http://www. psych. umass .edu/eyelab/software/. 
consists of the sum of all fixation durations following the first exit of the region (either to right or left).

For all eye-movement measures except second pass time, if on any given trial the region receives no fixations, then data for that trial is not included in the analysis. Moreover, for the first pass time and regression path time, if on any given trial the region is skipped before the first fixation occurs, then the data for that trial is not included in the analysis.

Data for the eye-movement measures were analyzed using Linear Mixed Effects Regression (LMER) analysis (Baayen, 2008; Baayen, Davidson, \& Bates, 2008; Jaeger, 2008), using the lme4 $\mathrm{R}$ package. One advantage of LMER is that it allows the simultaneous consideration of participants and items as random factors in a single analysis, thus avoiding the need for separate $F_{1}$ and $F_{2}$ and Min $F^{\prime}$ analyses. Moreover, LMER is robust in the face of missing data, a situation that is common in eye-tracking research.

For all experiments reported here, an LMER model was constructed, incorporating all fixed effects and their interactions in a single step. Factor labels were transformed into numerical values, and centered prior to analysis, so as to have a mean of 0 and a range of 1 . This procedure minimizes collinearity between variables (Baayen, 2008), and, in combination with sum coding of contrasts, allows coefficients to be interpreted in an analogous way to the main effects and interactions in an Analysis of Variance. The analysis yields coefficients, standard errors and $t$-values for each fixed effect and interaction. A given coefficient was judged to be significant if the absolute value of $t$ exceeded 2 (Baayen, 2008). ${ }^{4}$

The regression models for all experiments reported here incorporated crossed random intercepts for participants and items. Random slope parameters were included into the models using forward selection (Baayen, 2008) as LMER models that do not take random slopes into account can be anti-conservative. Random slope parameters for main effects and interactions were added sequentially, first for participants, and then for items. The final model incorporated only those random slope parameters whose inclusion resulted in a better model fit than simpler models. The inclusion of random slope estimates can lead to extremely complicated models, with many extra parameters, so it is important to justify the extra complexity of a model that includes such parameters. The forward selection procedure provided a good way of doing this, while minimizing problems due to failure of convergence for very complex models.

In Experiments 1 and 2 reported below, random slope parameters were added in the following order: NP2 main effect by participants; NP1 main effect by participants; NP1 $1 \times \mathrm{NP} 2$ interaction by participants; NP 2 main effect by items; NP1 main effect by items; NP1 $\times$ NP2 interaction by items. When evaluating random effects by items, the model included those participant-based random effects that had already been demonstrated to improve the model fit. Each successive pair of models was compared using a log-likelihood ratio test, evaluated against the $\chi^{2}$ distribution, taking as the degrees of freedom the difference in number of parameters between the two models (see Baayen, 2008, p. 276).

\section{Results}

Table 1 shows the empirical means for the four conditions in the critical and final regions, in the four eye-movement measures. Table 2 shows the results of the LMER analysis for the main

\footnotetext{
${ }^{4}$ We were not able to use Markov Chain Monte Carlo sampling to estimate $p$-values, because of the incorporation of random slope parameters. The $\mathrm{R}$ package lme 4 we used for model fitting does not yet support this combination of features.
} 
Table 1: Empirical means for the eye-movement measures in critical and final regions in Experiment 1 in milliseconds.

\begin{tabular}{lrcrc}
\hline & \multicolumn{2}{c}{ NP2=AdjP } & \multicolumn{2}{c}{ NP2=RelCl } \\
& NP1=AdjP & NP1=RelCl & NP1=AdjP & NP1=RelCl \\
\hline Critical region & & & & \\
First pass & 780 & 969 & 979 & 893 \\
Regression path & 929 & 1099 & 1168 & 1031 \\
Total time & 1155 & 1383 & 1413 & 1197 \\
Second pass & 381 & 414 & 440 & 305 \\
\hline Final region & & & & \\
First pass & 760 & 700 & 826 & 811 \\
Regression path & 1736 & 1880 & 1884 & 1587 \\
Total time & 979 & 1025 & 1046 & 966 \\
Second pass & 219 & 326 & 220 & 154 \\
\hline
\end{tabular}

effects and interactions.

In the critical NP2 region, all eye-movement measures showed a consistent numerical pattern: reading times were reduced when NP1 had the same structure as NP2. The typical pattern is illustrated in Figure 2, which shows the model estimates for total time. This pattern led to a significant interaction in all measures except second pass. In regression path time, there was also a main effect of NP2; the region was read approximately $84 \mathrm{~ms}$ more slowly when it included a relative clause, compared to when it included an adjective phrase. This difference is easily accounted for by the fact that the relative clause conditions included two more words than the adjective phrase conditions.

For each measure where an interaction was obtained, we will now explore the pattern of the interaction using pairwise comparisons. We report these comparisons for completeness, although, as mentioned above, it is hard to make strong conclusions about the symmetry or otherwise of the parallelism effect in this type of design. The pairwise comparisons are evaluated with respect to a 95\% confidence interval estimated as $2 \mathrm{SE}$, where SE is the standard error of the NP1 coefficient of the LMER model. ${ }^{5}$

In total time, adjective phrase NP2s were read $228 \mathrm{~ms}$ faster when preceded by an adjective phrase NP1 than by a relative clause NP1, while relative clause NP2s were read 216 ms more quickly when preceded by a relative clause NP1 than by an adjective phrase NP1. Both of these contrasts were significant $(\mathrm{CI}=116 \mathrm{~ms})$.

In first pass, adjective phrase NP2s were read $186 \mathrm{~ms}$ faster when preceded by an adjective phrase NP1 than by a relative clause NP1, while relative clause NP2s were read 86 ms more quickly when preceded by a relative clause NP1 than by an adjective phrase NP1. Both of these contrasts were significant $(\mathrm{CI}=66 \mathrm{~ms})$.

In regression path time, adjective phrase NP2s were read $170 \mathrm{~ms}$ faster when preceded by an adjective phrase. Conversely, relative clause NP2s were read $137 \mathrm{~ms}$ faster when preceded by an NP of the same form. Both of these contrasts were reliable $(\mathrm{CI}=68 \mathrm{~ms})$.

In the final region, first pass reading times showed no reliable effects. An interaction was

\footnotetext{
${ }^{5}$ This corresponds to a criterion for significance of $|t|>2$.
} 
Table 2: Linear mixed effect model result for Experiment 1. Coefficients, standard errors and $t$-values are reported for the main effects of NP1 and NP2, as well as the interaction of these two factors. The "Slope" column indicates whether the random slope parameter corresponding to the effect was included in the model for participants (p) or items (i). An asterisk indicates that the effect is significant (using the $|t|>2$ criterion).

\begin{tabular}{lrrrrrrrr}
\hline & \multicolumn{3}{c}{ Critical Region } & \multicolumn{5}{c}{ Final Region } \\
& Coeff & SE & $t$ & Slope & Coeff & SE & $t$ & Slope \\
\hline Total Time & & & & & & & & \\
(Intercept) & 1285 & 82 & $15.61^{*}$ & & 1003 & 57 & $17.68^{*}$ & \\
NP1 & 7 & 58 & 0.11 & $(\mathrm{p})$ & -18 & 36 & -0.48 & - \\
NP2 & 34 & 46 & 0.74 & $(\mathrm{p})$ & -1 & 36 & -0.02 & - \\
NP1 $\times$ NP2 & -424 & 83 & $-5.11^{*}$ & - & -120 & 73 & -1.65 & - \\
\hline First Pass & & & & & & & & \\
Intercept) & 904 & 50 & $18.15^{*}$ & & 775 & 46 & $16.78^{*}$ & \\
NP1 & 50 & 33 & 1.53 & - & -40 & 41 & -0.97 & $(\mathrm{p})$ \\
NP2 & 60 & 33 & 1.83 & - & 85 & 43 & 1.96 & $(\mathrm{p})$ \\
NP1 $\times$ NP2 & -273 & 66 & $-4.15^{*}$ & - & 51 & 65 & 0.78 & - \\
\hline Regression Path & & & & & & & & \\
Intercept) & 1055 & 56 & $18.92^{*}$ & & 1771 & 140 & $12.61^{*}$ & \\
NP1 & 14 & 34 & 0.42 & - & -65 & 79 & -0.83 & - \\
NP2 & 84 & 34 & 2.50 & - & -78 & 79 & -1.00 & - \\
NP1 $\times$ NP2 & -298 & 67 & $-4.43^{*}$ & - & -414 & 158 & $-2.63^{*}$ & - \\
\hline Second Pass & & & & & & & & \\
(Intercept) & 384 & 67 & 5.76 & & 230 & 31 & $7.46^{*}$ & \\
NP1 & -49 & 39 & -1.24 & - & 22 & 30 & 0.73 & - \\
NP2 & -26 & 39 & -0.66 & - & -86 & 30 & -2.85 & - \\
NP1 $\times$ NP2 & -152 & 78 & -1.94 & - & -173 & 60 & $-2.88^{*}$ & - \\
\hline & & & & & & & &
\end{tabular}

obtained in both regression path time and second pass time (note that as this is the final region, differences must come from trials in which the participant regressed leftward out of the final region and subsequently fixated the final region again, following a rightward saccade). These interactions resulted from a similar data pattern to that observed in the critical region, with reading times faster when the region was preceded by two syntactically congruent NPs than when it was not. In regression path times, the pairwise comparison was only reliable for the conditions where the NP2 included a relative clause $(\mathrm{CI}=158 \mathrm{~ms})$, while for second pass, the comparison was reliable for both contrasts $(\mathrm{CI}=60 \mathrm{~ms}$ ). Descriptively, a similar interactive pattern was observed in the total time means, but this failed to reach significance.

\section{Discussion}

The results show a clear processing advantage for second conjuncts that share a syntactic form with the first conjunct. For total time and regression path time in the critical region, this advantage is observed regardless of whether the second conjunct itself is in the more marked adjectival phrase form, or whether it is in the less marked relative clause form. For first pass time, the advantage could be established only for second conjuncts with the more marked adjectival phrase form. One notable 


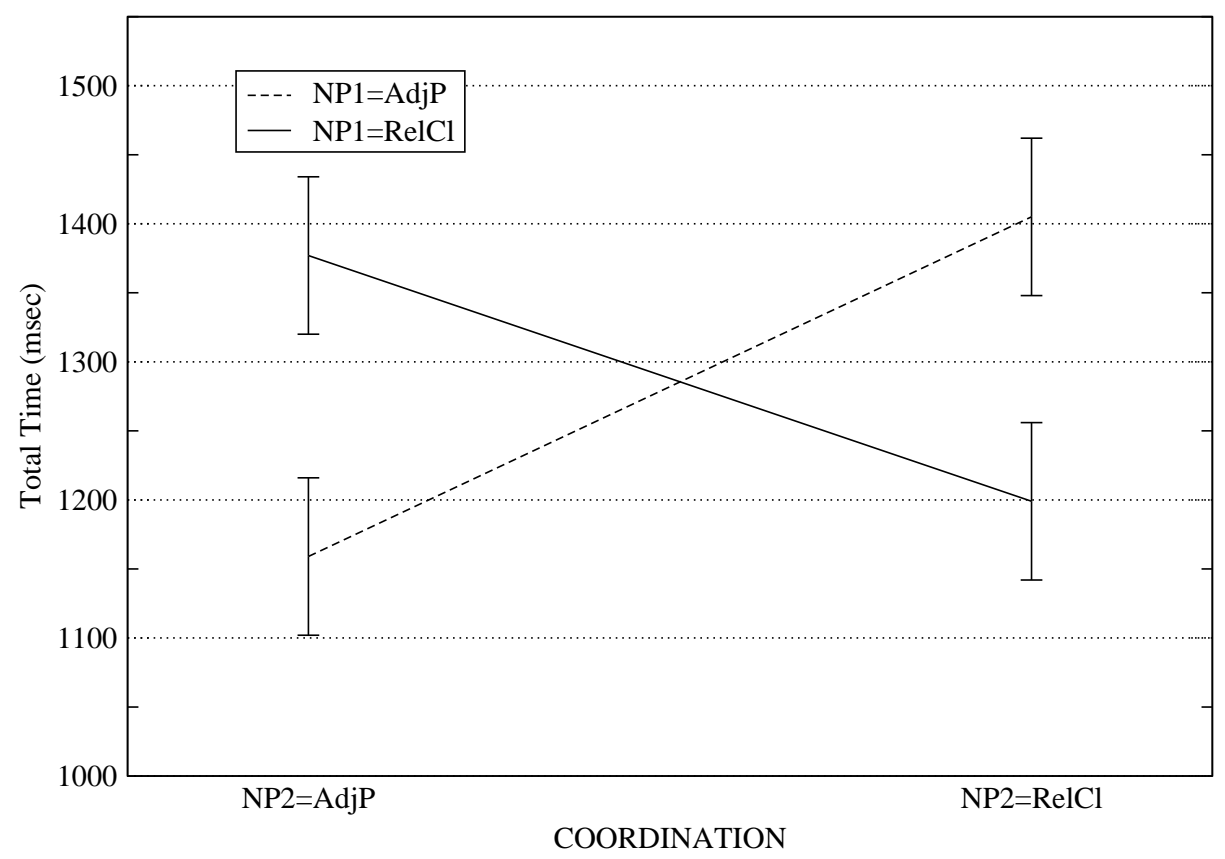

Figure 2. Total time in the critical region for Experiment 1. Error bars show +/- 1 standard error of the NP1 coefficient of the LMER model.

aspect of the results is that the more marked adjectival phrase form apparently never led to slower reading times. However, it should be noted that the relative clause conditions were consistently two words longer. Thus, the relative paucity of evidence for slower processing of the longer conditions can be seen as indirect confirmation of the markedness of the adjectival forms. We will take up this point again in the next experiment.

\section{Experiment 2}

Experiment 1 replicated the parallelism effect in coordination reported in the literature. In contrast to earlier studies (e.g., Frazier et al., 2000), we used structures that are truth conditionally equivalent (adjectival phrases and relative clauses), thus ruling out a semantic explanation of the parallelism effect. Furthermore, Experiment 1 employed a symmetric design in which both variants of the target structure occurred either in a parallel or in a non-parallel condition. This enabled us to rule out length and spill-over artifacts as alternative explanations of the parallelism effect.

The current experiment builds on this result, and extends the investigation of parallelism effects to non-coordinated structures. Recall from the introduction that Frazier et al. (2000) failed to find a parallelism effect in cases where the first phrase is the subject and the second phrase is the object of a sentence. However, we argued that this does not necessarily rule out parallelism effects in other structures, in particular when the two phrases share the same grammatical function (e.g., they are both subjects). Furthermore, we noted that previous studies showed the non-existence of parallelism effects outside coordination based on between-experiment comparisons involving a null effect in one of the experiments. This leaves open lack of power as an alternative explanation. It is conceivable, for instance, that parallelism effects are weaker outside coordination, hence more power is required to detect them. 
Experiment 2 was designed to address these problems. We again use truth conditionally equivalent structures (adjective phrases and relative clauses), but this time the two phrases in question are embedded in a subordination environment: the first phrase is the subject of the main clause, the second one the subject of the subordinate clause. As in Experiment 1, a fully crossed design is employed which compares parallel and non-parallel structures in the same experiment. We also decided to increase the power of the experimental design by doubling the number of stimuli; this makes it more likely that we will be able to detect an effect even if parallelism is weaker outside coordination, which could explain the null effects in previous experiments in the literature. Because of the difficulty of creating large numbers of stimuli using the tough-construction, Experiment 2 used a less marked syntactic alternation, comparing simple adjective phrases and relative clauses (Cleland \& Pickering, 2003 used the same structures to study priming in production). This choice has the additional benefit of allowing us to examine parallelism effects without relying on highly unusual or quasi-ungrammatical sentences, thus allowing the opportunity to make stronger conclusions on the generality of the findings.

Participants. Twenty-eight new participants from the University of Edinburgh community were paid to take part in the experiment.

Stimuli. The 48 experimental items in this experiment were similar to those of Experiment 1, except that simple relative clauses and adjective phrases were used as the alternating structures, rather then tough-constructions (see Appendix for a full list). We only included subordinating NPs in the design, as Experiment 1 established conclusively that coordinated NPs show the parallelism effect. A set of example stimuli is given in (7).

a. $\quad N P 1=A d j P ; N P 2=A d j P$

A demanding boss said that a lazy worker did not do the job properly.

b. $\quad N P 1=R e l C l ; N P 2=A d j P$

A boss who was demanding said that a lazy worker did not do the job properly.

c. $\quad N P 1=\operatorname{AdjP} ; N P 2=\operatorname{RelCl}$

A demanding boss said that a worker who was lazy did not do the job properly.

d. $\quad N P 1=$ RelCl; $N P 2=\operatorname{RelCl}$

A boss who was demanding said that a worker who was lazy did not do the job properly.

The design therefore involved a full crossing of factors NP1 and NP2. Twenty-four of the stimuli were adapted from the stimuli of Experiments 2 and 3, the remaining twenty-four were new.

Procedure. The procedure was identical to that of Experiment 1, except that the number of fillers was increased to 72. Of the fillers, 48 were from two unrelated experiments on garden pathing and agreement errors. The extra fillers from other experiments were ad ded so that no two items from any given experiment would appear adjacent to each other.

Data Analysis. Data analysis was analogous to that of Experiment 1.

\section{Results}

Table 3 shows the empirical means for the four conditions in the critical and final regions, in the four eye-movement measures. Table 4 shows the results of the LMER analysis for the main effects and interactions. 
Table 3: Empirical means for the eye-movement measures in critical and final regions in Experiment 2 in milliseconds.

\begin{tabular}{lcccc}
\hline & \multicolumn{2}{c}{ NP2=AdjP } & \multicolumn{2}{c}{ NP2=RelCl } \\
& NP1=AdjP & NP1=RelCl & NP1=AdjP & NP1=RelCl \\
\hline Critical Region & & & & \\
Total Time & 611 & 625 & 1085 & 1002 \\
First Pass & 430 & 404 & 643 & 634 \\
Regression Path & 515 & 552 & 886 & 873 \\
Second Pass & 180 & 224 & 440 & 367 \\
\hline Final Region & & & & \\
Total Time & 1165 & 1184 & 1183 & 1127 \\
First Pass & 962 & 960 & 890 & 887 \\
Regression Path & 1570 & 1653 & 1745 & 1641 \\
Second Pass & 201 & 223 & 291 & 238 \\
\hline
\end{tabular}

There were two basic results of the experiment. First, the NP2 was read reliably more slowly when it had the relative clause form than when it had the adjective phrase form. This effect was obtained in all measures in the critical region. However, it is of limited theoretical interest, and is almost certainly due to the fact that the NP2 was two words longer in the relative clause condition than in the adjective phrase condition.

The second basic result of the experiment was a reliable interaction of $N P 1$ and $N P 2$, which is illustrated by the total time data shown in Figure 3. The interaction, which was reliable in the critical region in total time and second pass is consistent with a parallelism effect. Reading times for the NP2 were numerically slower when preceded by an NP1 of a different syntactic form than when the NP1 had the same form. The parallelism advantage was asymmetrical, being numerically larger when the NP2 included a relative clause (total time: $79 \mathrm{~ms}$; second pass: $71 \mathrm{~ms}$ ) than when it included an adjective phrase (total time: $13 \mathrm{~ms}$; second pass: $44 \mathrm{~ms}$ ), and only the former contrasts were reliable, based on the standard errors of the NP1 coefficient $(\mathrm{CI}=46 \mathrm{~ms}$, for both total time and second pass).

\section{Discussion}

Experiment 2 provided evidence for parallelism effects in a syntactic context unrelated to coordination. In analogy to Experiment 1, we manipulated the structure of the first NP and the second NP, but these now stood in a subordinating relationship rather than being coordinated. An interaction between the NP1 factor and the NP2 factor was obtained in total time and second pass in the critical region. As in Experiment 1, this indicates the presence of a parallelism effect.

The magnitude of the effect is clearly smaller than that seen in Experiment 1, and it is likely that a relatively powerful experimental design is required to detect it. This could explain why previous authors such as Frazier et al. (2000) and Apel et al. (2007) did not detect parallelism effects outside coordination. Furthermore, we saw that the effect is asymmetric; in total time and second pass, the parallelism speed-up was only detectable when the NP2 was a relative clause. This contrasts with Experiment 1, where the parallelism advantage was found for both types of NP2. Although we cannot make strong conclusions on the basis of the individual pairwise comparisons in this type of 
Table 4: Linear mixed effect model results for Experiment 2. Coefficients, standard errors and $t$-values are reported for the main effects of NP1 and NP2, as well as the interaction of these two factors. The "Slope" column indicates whether the random slope parameter corresponding to the effect was included in the model for participants (p) or items (i). An asterisk indicates that the effect is significant (using the $|t|>2$ criterion).

\begin{tabular}{lrrrrrrrr}
\hline & \multicolumn{3}{c}{ Critical Region } & \multicolumn{5}{c}{ Final Region } \\
& Coeff & SE & $t$ & Slope & Coeff & SE & $t$ & Slope \\
\hline Total Time & & & & & & & & \\
(Intercept) & 831 & 53 & $15.68^{*}$ & & 1164 & 55 & $21.35^{*}$ & \\
NP1 & -33 & 23 & -1.44 & - & -16 & 27 & -0.61 & - \\
NP2 & 426 & 32 & $13.32^{*}$ & $(\mathrm{p})$ & -19 & 27 & -0.72 & - \\
NP1 $\times$ NP2 & -92 & 46 & $-2.03^{*}$ & - & -74 & 53 & -1.39 & - \\
\hline First Pass & & & & & & & & \\
(Intercept) & 528 & 26 & $20.22^{*}$ & & 924 & 48 & $19.43^{*}$ & \\
NP1 & -17 & 15 & -1.10 & - & 0 & 22 & -0.01 & - \\
NP2 & 221 & 20 & $11.33^{*}$ & $(\mathrm{p})$ & -74 & 22 & $-3.33^{*}$ & - \\
NP1 $\times$ NP2 & 19 & 31 & 0.63 & - & 1 & 44 & 0.02 & - \\
\hline Regression Path & & & & & & & & \\
(Intercept) & 707 & 38 & $18.68^{*}$ & & 1650 & 113 & $14.62^{*}$ & \\
NP1 & 12 & 20 & 0.61 & - & -5 & 54 & -0.09 & - \\
NP2 & 347 & 32 & $10.75^{*}$ & $(\mathrm{p})$ & 84 & 54 & 1.56 & - \\
NP1 $\times$ NP2 & -47 & 40 & -1.17 & - & -186 & 108 & -1.73 & - \\
\hline Second Pass & & & & & & & & \\
(Intercept) & 303 & 44 & $6.85^{*}$ & & 239 & 39 & $6.18^{*}$ & \\
NP1 & -14 & 23 & -0.61 & - & -16 & 38 & -0.42 & $(\mathrm{i})$ \\
NP2 & 202 & 34 & $6.00^{*}$ & $(\mathrm{p})$ & 53 & 28 & 1.87 & $(\mathrm{p}, \mathrm{i})$ \\
NP1 $\times$ NP2 & -115 & 45 & $-2.54^{*}$ & - & -76 & 49 & -1.55 & - \\
\hline
\end{tabular}

design, we believe that this lack of symmetry may be a consequence of the much smaller size of the parallelism effect seen in the current experiment in comparison with that of Experiment 1.

One other aspect of the experimental results that deserves comment is the large effect of the NP2 on the eye-movement measures. This effect, which is likely due to the extra length in the relative clause conditions, contrasts with the much smaller difference seen in Experiment 1, even though the relative clauses there were also two words longer than the adjective phrases. The contrast in the size of these effects confirms the highly marked nature of the adjective phrase construction in conjunction with tough-movement, in contrast to the less marked adjective phrase construction used in Experiment 2.

\section{Experiment 3}

Experiment 3 had two aims. The first purpose was to replicate the results of Experiment 2. Although the parallelism effect in Experiment 2 was statistically reliable, the effect was relatively small, so replication was crucial to rule out a Type I error. The second purpose of Experiment 3 was to make an explicit comparison of the parallelism effect between coordination and subordination 


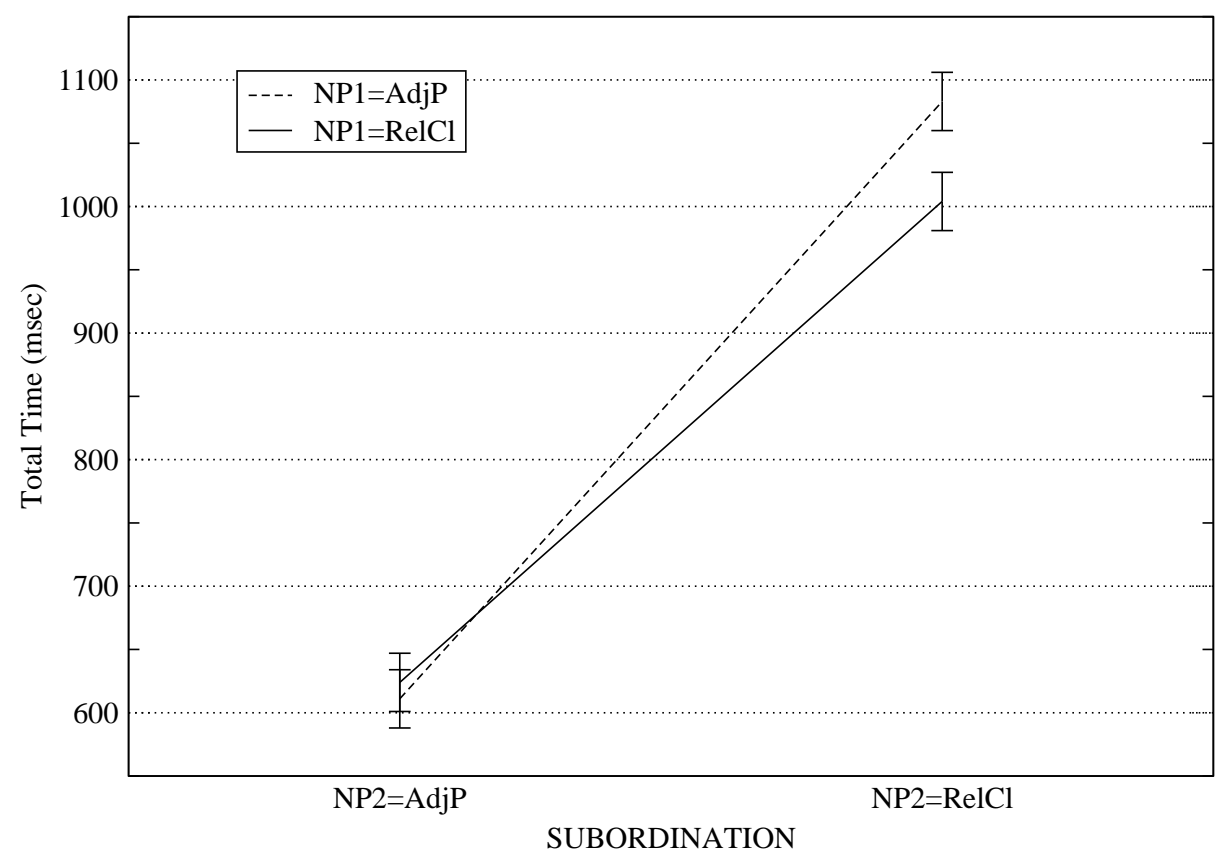

Figure 3. Total time in the critical region for Experiment 2. Error bars show +/- 1 standard error of the NP1 coefficient of the LMER model.

environments within the same experiment. This is important as the two previous experiments investigated parallelism in related, but not identical NP structures: Experiment 1 used NPs involving tough-movement, while Experiment 2 relied on unmarked adjectival phrases and relative clauses. It is therefore possible that the relative weakness of the parallelism effect in subordination (which was only reliable with relative clause targets) is due to differences in NP structure. An alternative hypothesis is that parallelism effects are generally stronger in coordination than in subordination. A design that directly compares the two types of environments in a single experiment is ideal for settling this questions.

The design of the present experiment therefore replicated the crossed design of Experiment 2, as well as including an additional factor of sentence structure (subordination vs. coordination). This is illustrated in the example item in (8):

a. $\quad N P 1=\operatorname{AdjP} ; N P 2=\operatorname{AdjP} ;$ Coordination

A demanding boss and a lazy worker did not do the job properly.

b. $\quad N P 1=R e l C l ; N P 2=A d j P ;$ Coordination

A boss who was demanding and a lazy worker did not do the job properly.

c. $\quad N P 1=\operatorname{Adj} P ; N P 2=$ RelCl; Coordination

A demanding boss and a worker that was lazy did not do the job properly.

d. $\quad N P 1=R e l C l ; N P 2=$ RelCl; Coordination

A boss who was demanding and a worker that was lazy did not do the job properly.

e. $\quad N P 1=A d j P ; N P 2=A d j P ;$ Subordination

A demanding boss said that a lazy worker did not do the job properly.

f. $\quad N P 1=\operatorname{RelCl} ; N P 2=$ AdjP; Subordination 
A boss who was demanding said that a lazy worker did not do the job properly.

g. $\quad N P 1=\operatorname{AdjP} ; N P 2=$ RelCl; Subordination

A demanding boss said that a worker who was lazy did not do the job properly.

h. $\quad N P 1=R e l C l ; N P 2=R e l C l ;$ Subordination

A boss who was demanding said that a worker who was lazy did not do the job properly.

Based on Experiments 1 and 2, we assume that the parallelism effect will be obtained for the coordination conditions, and this will correspond to a NP1 $\times$ NP2 interaction. The theoretically important question is whether this effect is larger in size than the corresponding NP1 $1 \times \mathrm{NP} 2$ interaction for the subordination condition. There are at least three possible outcomes of this comparison. First, if the results of Experiment 2 were due to a Type I error, we would expect a three-way interaction $\mathrm{NP} 1 \times \mathrm{NP} 2 \times$ Structure, in which the parallelism effect is reliable only for the coordination structure, and not for the subordination structure. This would support the claim that the parallelism effect is limited to coordination. The second possibility is that there is a parallelism effect for both subordination and coordination, but that the effect is larger for coordination than for subordination. This would also result in a three-way interaction. The third possibility is that the parallelism effect is of an equal magnitude for coordination and subordination. In this case, only the NP1 $\times$ NP2 interaction, but no three-way interaction, is predicted.

Note that the use of a $2 \times 2 \times 2$ design results in a total of 8 experimental conditions (compared to the 4 conditions in Experiments 1 and 2). We therefore increased the number of participants and items, in order to obtain a design with a similar level of power to that of the two previous experiments.

Participants. Forty-eight new participants from the University of Edinburgh community were paid to take part in the experiment.

Stimuli. Ninety-six stimuli were prepared, with manipulations equivalent to those shown in (8). Half (48) of these stimuli were taken from Experiment 2, either directly, or with minor modifications, and the other half was new.

Procedure. Experiment 3 was run using an Eyelink 1000 eye-tracker, rather than the Eyelink II used in the previous experiments. The Eyelink 1000 has a higher temporal resolution than the Eyelink $2(1000 \mathrm{~Hz}$ instead of $500 \mathrm{~Hz})$, and is also less affected by spatial drift in the fixation data. Eye movements were recorded from the right eye only.

Eight lists were created by Latin square rotation, such that each list contained a distinct condition of each of the 96 items, and an equal number of each of the eight conditions appeared in any given list. The experimental items were combined with 152 filler stimuli, of which 28 were from an unrelated experiment on syntactic garden paths. The experiment typically lasted over an hour.

Apart from these details, the procedure was identical to that of Experiments 1 and 2.

Data Analysis. Data analysis was analogous to that of Experiments 1 and 2. Random effect structure was determined on the basis of the following order of inclusion of random slope parameters: Main effect of NP2; Main effect of NP1; Main effect of Structure; Interaction of NP1 $\times$ NP2; Interaction of NP1 $\times$ Structure; Interaction of NP $2 \times$ Structure. As with the previous two experiments, the random slope parameters were first selected for participants, and then the chosen parameters were held in place while the item random effect structure was tested. We did not include random 
Table 5: Empirical means for the eye-movement measures in critical and final regions in Experiment 3 in milliseconds.

\begin{tabular}{lllccc}
\hline & & \multicolumn{2}{c}{ NP2 $=$ AdjP } & \multicolumn{2}{c}{ NP2=RelCl } \\
& & NP1=AdjP & NP1=RelCl & NP1=AdjP & NP1=RelCl \\
\hline Critical Region & & & & & \\
Total Time & (coordination) & 677 & 717 & 1027 & 919 \\
& (subordination) & 635 & 670 & 1032 & 959 \\
First Pass & (coordination) & 472 & 496 & 678 & 648 \\
& (subordination) & 445 & 452 & 660 & 631 \\
Regression Path & (coordination) & 557 & 590 & 809 & 778 \\
& (subordination) & 560 & 594 & 836 & 852 \\
Second Pass & (coordination) & 204 & 222 & 350 & 271 \\
& (subordination) & 190 & 218 & 382 & 330 \\
\hline Final Region & & & & & \\
Total Time & (coordination) & 1270 & 1319 & 1262 & 1248 \\
\multirow{5}{*}{ First Pass } & (subordination) & 1232 & 1217 & 1304 & 1244 \\
\multirow{5}{*}{ Regression Path } & (coordination) & 1049 & 1033 & 979 & 1041 \\
\multirow{5}{*}{ Second Pass } & (subordination) & 1006 & 969 & 962 & 999 \\
& (coordination) & 1674 & 1820 & 1749 & 1708 \\
& (subordination) & 1646 & 1724 & 1903 & 1744 \\
& (coordination) & 221 & 287 & 283 & 206 \\
& (subordination) & 225 & 247 & 344 & 245 \\
\hline
\end{tabular}

slopes for the three-way interaction, due to convergence problems. This is probably due to the high complexity of such models. ${ }^{6}$

\section{Results}

Table 5 shows the empirical means for the four conditions in the critical and final regions, in the four eye-movement measures. Table 6 shows the results of the LMER analysis for the main effects and interactions.

To save space, we will limit our discussion to effects that are of theoretical interest.

Critical Region. The main finding of this experiment was the interaction of NP1 $\times$ NP2, which was reliable for all the eye-movement measures in the critical region. The pattern of this interaction is consistent with a parallelism advantage-reading times for NP2 were shorter when preceded by an NP1 of the same form than when NP1 had a different form. The second notable result of this experiment is the lack of a three-way interaction between the variables, indicating that the magnitude of the parallelism preference is not statistically distinguishable between coordination and subordination, at least for the types of sentences considered here. This pattern of results is illustrated by the Total Time results for the critical region shown in Figure 4.

\footnotetext{
${ }^{6} \mathrm{~A}$ full model, including the three-way interaction and all lower-order effects, plus all possible random slope parameters for participants and items, has 81 parameters.
} 
Table 6: Linear mixed effect model result for Experiment 3. Coefficients, standard errors and $t$-values are reported for the main effects of NP1 and NP2, as well as the interaction of these two factors. The "Slope" column indicates whether the random slope parameter corresponding to the effect was included in the model for participants (p) or items (i). An asterisk indicates that the effect is significant (using the $|t|>2$ criterion).

\begin{tabular}{|c|c|c|c|c|c|c|c|c|}
\hline & \multicolumn{4}{|c|}{ Critical Region } & \multicolumn{4}{|c|}{ Final Region } \\
\hline & Coeff & $\mathrm{SE}$ & $t$ & Slope & Coeff & SE & $t$ & Slope \\
\hline $\begin{array}{l}\text { Total Time } \\
\text { (Intercept) }\end{array}$ & 836 & 34 & $24.29^{*}$ & & 1268 & 54 & $23.60^{*}$ & \\
\hline NP1 & -27 & 15 & -1.82 & $(\mathrm{p}, \mathrm{i})$ & -12 & 18 & -0.65 & (p) \\
\hline NP2 & 312 & 21 & $15.02^{*}$ & $(\mathrm{p}, \mathrm{i})$ & 6 & 18 & 0.32 & (p) \\
\hline Struc & -11 & 17 & -0.66 & - & -23 & 18 & -1.27 & - \\
\hline $\mathrm{NP} 1 \times \mathrm{NP} 2$ & -128 & 47 & $-2.73^{*}$ & $(\mathrm{p}, \mathrm{i})$ & -47 & 61 & -0.77 & (p) \\
\hline $\mathrm{NP} 1 \times$ Struc & 16 & 26 & 0.60 & - & -50 & 36 & -1.39 & - \\
\hline $\mathrm{NP} 2 \times$ Struc & 70 & 26 & $2.64^{*}$ & - & 97 & 36 & $2.69^{*}$ & - \\
\hline $\mathrm{NP} 1 \times \mathrm{NP} 2 \times$ Struc & 45 & 53 & 0.86 & - & 9 & 72 & 0.12 & - \\
\hline $\begin{array}{l}\text { First Pass } \\
\text { (Intercept) }\end{array}$ & 565 & 22 & $25.78^{*}$ & & 1009 & 40 & $25.00^{*}$ & \\
\hline NP1 & -8 & 8 & -1.04 & 一 & 10 & 13 & 0.73 & - \\
\hline NP2 & 192 & 14 & $14.20^{*}$ & $(\mathrm{p}, \mathrm{i})$ & -17 & 13 & -1.29 & - \\
\hline Struc & -26 & 8 & $-3.45^{*}$ & - & -39 & 16 & $-2.46^{*}$ & (i) \\
\hline $\mathrm{NP} 1 \times \mathrm{NP} 2$ & -44 & 15 & $-2.86^{*}$ & - & 78 & 26 & $2.95^{*}$ & - \\
\hline $\mathrm{NP} 1 \times$ Struc & -7 & 15 & -0.46 & - & -22 & 26 & -0.83 & - \\
\hline $\mathrm{NP} 2 \times$ Struc & 20 & 15 & 1.28 & - & 29 & 26 & 1.09 & - \\
\hline $\mathrm{NP} 1 \times \mathrm{NP} 2 \times$ Struc & 21 & 31 & 0.67 & - & -8 & 53 & -0.16 & - \\
\hline $\begin{array}{l}\text { Regression Path } \\
\text { (Intercept) }\end{array}$ & 703 & 31 & $22.99^{*}$ & & 1758 & 91 & $19.27^{*}$ & \\
\hline NP1 & 12 & 10 & 1.23 & (i) & 7 & 40 & 0.17 & (p) \\
\hline NP2 & 249 & 20 & $12.63^{*}$ & $(\mathrm{p}, \mathrm{i})$ & 60 & 38 & 1.58 & (p) \\
\hline Struc & 28 & 11 & $2.63^{*}$ & (i) & 20 & 38 & 0.53 & - \\
\hline $\mathrm{NP} 1 \times \mathrm{NP} 2$ & -39 & 18 & $-2.13^{*}$ & - & -204 & 158 & -1.29 & (p) \\
\hline $\mathrm{NP} 1 \times$ Struc & 25 & 18 & 1.38 & - & -87 & 76 & -1.15 & - \\
\hline $\mathrm{NP} 2 \times$ Struc & 51 & 18 & $2.77^{*}$ & 一 & 168 & 76 & $2.21^{*}$ & 一 \\
\hline $\mathrm{NP} 1 \times \mathrm{NP} 2 \times$ Struc & 50 & 37 & 1.36 & - & -64 & 152 & -0.42 & - \\
\hline $\begin{array}{l}\text { Second Pass } \\
\text { (Intercept) }\end{array}$ & 273 & 24 & $11.25^{*}$ & & 258 & 27 & $9.63^{*}$ & \\
\hline NP1 & -21 & 14 & -1.54 & (p) & -22 & 19 & -1.18 & $(\mathrm{p}, \mathrm{i})$ \\
\hline NP2 & 125 & 18 & $7.08^{*}$ & (p) & 24 & 18 & 1.37 & (p) \\
\hline Struc & 19 & 14 & 1.38 & (p) & 16 & 18 & 0.89 & - \\
\hline $\mathrm{NP} 1 \times \mathrm{NP} 2$ & -89 & 43 & $-2.08^{*}$ & (p) & -133 & 52 & $-2.54^{*}$ & (p) \\
\hline $\mathrm{NP} 1 \times$ Struc & 19 & 26 & 0.71 & - & -31 & 35 & -0.89 & - \\
\hline $\mathrm{NP} 2 \times$ Struc & 57 & 26 & $2.17^{*}$ & - & 70 & 35 & $2.00^{*}$ & - \\
\hline $\mathrm{NP} 1 \times \mathrm{NP} 2 \times$ Struc & 18 & 52 & 0.34 & - & 21 & 70 & 0.30 & - \\
\hline
\end{tabular}




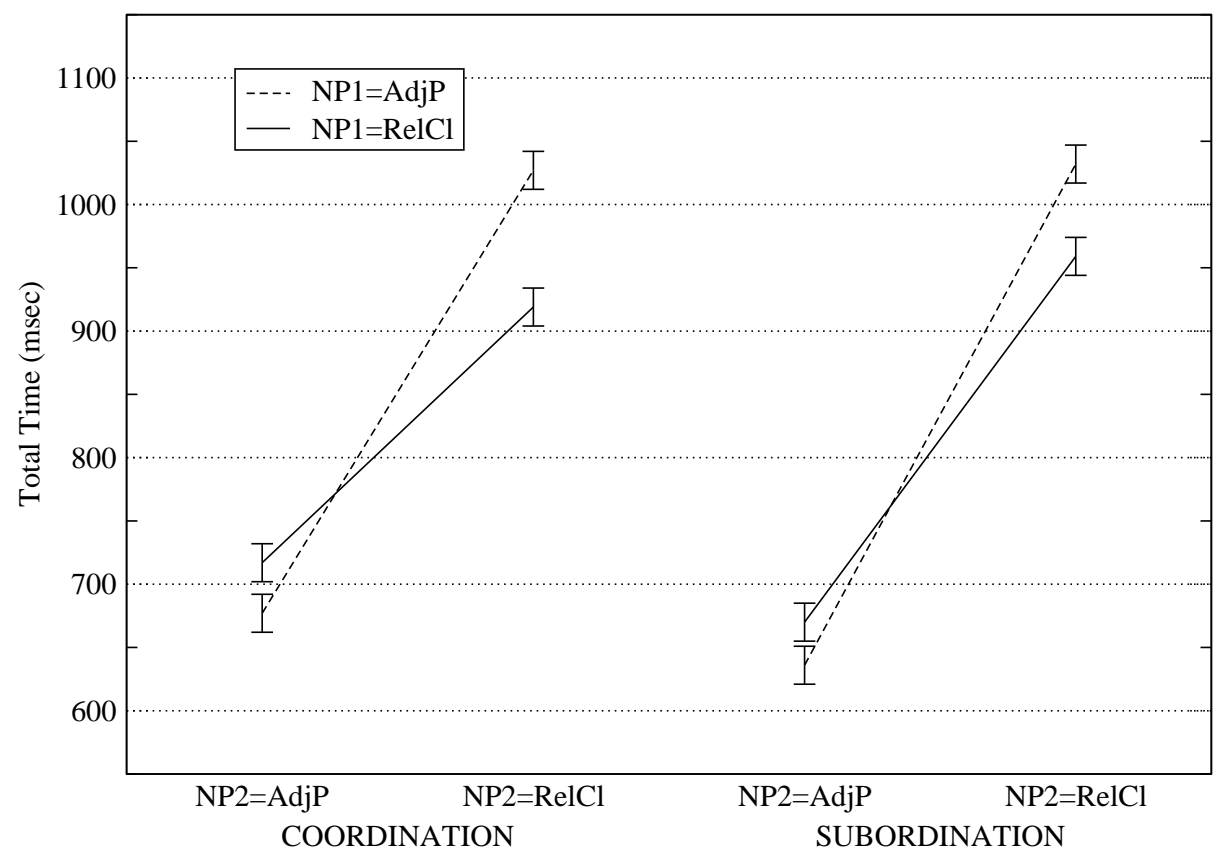

Figure 4. Total time in the critical region for Experiment 3. Error bars show +/- 1 standard error of the NP1 coefficient of the LMER model.

In order to make a closer examination of the parallelism effects for the two types of syntactic contexts, we looked at the NP1 $\times \mathrm{NP} 2$ interaction individually for the coordination and subordination conditions. This was done by examining the predicted means of the LMER model, and calculating the numerical magnitude of the NP1 $\times \mathrm{NP} 2$ interaction separately for the coordination and subordination conditions. ${ }^{7}$ These values were then compared against the $95 \%$ confidence interval derived from the NP1 $\times \mathrm{NP} 2$ interaction in the overall analysis to determine whether the parallelism effect can be considered significant individually for coordination and subordination. Based on this criterion, the parallelism effect was reliable for both subordination and coordination in total time (Coordination: $-151 \mathrm{~ms}$; Subordination: $-106 \mathrm{~ms}$; CI $=94 \mathrm{~ms}$ ), and in first pass (Coordination: $-54 \mathrm{~ms}$; Subordination: $-33 \mathrm{~ms} ; \mathrm{CI}=30 \mathrm{~ms}$ ), though it was only reliable for coordination in second pass (Coordination: $-98 \mathrm{~ms}$; Subordination: $-80 \mathrm{~ms}$; $\mathrm{CI}=86 \mathrm{~ms}$ ) and in regression path time (Coordination: $-64 \mathrm{~ms}$; Subordination: $-14 \mathrm{~ms}$; CI $=36 \mathrm{~ms}$ ).

For completeness, we also asked whether the parallelism effect is reliable for both forms of NP2. To answer this question, we examined the magnitude of the effect of NP1 separately for when NP2 had the relative clause form, and for when NP2 had the adjective phrase form (collapsing over coordination and subordination), and compared the effects against the confidence interval computed from the effect of NP1 in the overall analysis, in an analogous way to the contrast analysis reported above. This analysis showed that the effect was symmetrical for total time (AdjP: $-37 \mathrm{~ms}$; RelCl: $91 \mathrm{~ms} ; \mathrm{CI}=30 \mathrm{~ms}$ ). However, for first pass and second pass, the advantage was reliable only when NP2 had the relative clause form: first pass (AdjP: $-14 \mathrm{~ms}$; RelCl: $30 \mathrm{~ms} ; \mathrm{CI}=16 \mathrm{~ms}$ ); second pass (AdjP: $-23 \mathrm{~ms}$; RelCl: $65 \mathrm{~ms}$; CI $=28 \mathrm{~ms}$ ). The regression path measure, on the other hand, only

\footnotetext{
${ }^{7}$ The magnitude of the interaction is estimated as (AdjAdj - RelAdj) - (AdjRel - RelRel). This value corresponds to the coefficient for the NP1 $\times \mathrm{NP} 2$ interaction.
} 
showed the parallelism advantage when NP2 had the adjective phrase form (AdjP: $-32 \mathrm{~ms}$; RelCl: $7 \mathrm{~ms}$; CI = $20 \mathrm{~ms}$ ).

Apart from the NP1 $\times$ NP2 interaction, the critical region also showed a main effect of NP2 in all eye-movement measures, such that reading times were longer when NP2 had the relative clause form than the adjective phrase form. As with Experiment 2, this is almost certainly related to the fact that the NP2 included two extra words in the relative clause form compared with the adjective phrase form.

The critical region also showed an interaction of NP $2 \times$ Structure, in all of the eye-movement measures except first pass. The slow-down for relative clauses compared with adjective phrases was of a greater magnitude in the subordination conditions than in the coordination conditions. One possible interpretation of this effect is due to the relative complexity of the sentence structures involved. It is possible that the cost of predicting a main verb is lower than the cost of predicting a subordinate verb (Gibson, 1998) for the relevant subject NP. If so, then the storage cost will be higher in the subordination conditions than the coordination conditions at NP2. The extra complexity of the relative clause structure compared with the adjective phrase structure may interact with the storage cost differences to yield the observed pattern of results.

Final Region. In the final region, the NP1 $\times$ NP2 interaction was reliable for second pass, again with NP2 being read more quickly when NP1 had the same structure than when NP1 had a different structure. We analyzed the interaction separately for coordination and subordination conditions in an analogous way to that reported above for the critical region. This comparison showed that the coefficient corresponding to this interaction was reliable both for coordination and for subordination (Coordination: $-143 \mathrm{~ms}$; Subordination: $-122 \mathrm{~ms}$; CI =104 ms). There was no three-way interaction.

One effect that requires comment is the significant NP1 1 NP2 interaction in first pass times, which showed the opposite pattern from that predicted by parallelism: first pass times in the critical region were longer when NP1 and NP2 shared a structure than when they did not. We believe that this inconsistency is an artifact related to the incidence of first-pass regressions out of the final region. A follow-up analysis examined the interaction of NP1 $\times \mathrm{NP} 2$ separately for trials in which a first-pass regression occurred (59\% of the total), compared with trials without first-pass regressions $(41 \%)$. There was no statistical evidence of an interaction in the trials without regressions out of the final region $(|t|<1)$ (AdjAdj: 1113 ms; RelAdj: 1081 ms; AdjRel: 1077 ms; RelRel: 1087 ms). However, there was an interaction, matching the overall first-pass pattern in the trials in which a regression occurred $(t=2.60, p<.05)$ (AdjAdj: 968 ms; RelAdj: 944 ms; AdjRel: 903 ms; RelRel: $969 \mathrm{~ms})$.

One possible interpretation of this pattern is that regressions tended to be launched earlier out of the final region when the structure of NP2 differed from that of NP1, compared with conditions when the two NPs matched. This would lead to the observed pattern of first-pass times because, if a regression is launched relatively early in the reading of the region, the first pass duration will be relatively short, possibly reflecting the time of a single fixation. On the other hand, if a regression is launched relatively late, the first pass time will reflect the sequence of (possibly many) fixations that are made before the regression is launched. Evidence supporting this conclusion comes from two sub-analyses of first pass regressions out of the final region. The first analysis compared the proportion of trials on which an immediate first-pass regression occurred (operationalized as a regression that was launched immediately after the first (first pass) fixation the region). The second analy- 
sis compared the proportion of non-immediate regressions (operationalized as regressions launched after more than one first-pass fixation had been made in the region). There were more immediate regressions when the two NPs had a different structure than when they had the same structure (AdjAdj: 6\%; RelAdj: 9\%; AdjRel: 11\%; RelRel: 7\%), leading to a reliable NP1 $\times$ NP2 interaction in a logistic mixed effect regression $(Z=3.65, p<.001)^{8}$, matching the parallelism effect reported elsewhere in this paper. There was no three-way interaction, indicating that the parallelism effect did not statistically differ between subordinate and coordinated conditions $(Z=1.12, p=.26)$.

In contrast, there were no reliable differences in proportions of non-immediate regressions as a function of NP1 or NP2, or the interaction between these factors (all $p$ 's > .1; AdjAdj: 53\%; RelAdj: 50\%; AdjRel: 51\%; RelRel: 49\%).

Thus, assuming that processing difficulty is correlated with the earliness of the launch of a regression, the initially puzzling first-pass times are in fact consistent with the difficulty of unlike NP structures.

\section{Discussion}

Experiment 3 had two goals: to replicate the parallelism effect for subordination reported in Experiment 2, and to compare this effect with the parallelism effect for coordination. The results for the critical region replicate those of Experiment 2: all the eye-movement measures show an interaction effect consistent with parallelism, which is statistically indistinguishable between coordination and subordination. Moreover, for total time and first pass in the critical region, and for second pass in the final region, the relevant coefficients for both subordination and coordination were each reliable when considered separately.

We also observed that the magnitude of the parallelism coefficient was numerically smaller for subordination than for coordination, in all measures in which a parallelism effect was found (see Figure 4, for example). Despite the lack of three-way interactions, it is possible that further experimentation will be able to show that the degree of parallelism is larger in the coordination environment than the subordination environment. However, this does not necessarily imply that different mechanism underlies the parallelism effects in the two environment; we will return to this issue in the General Discussion below.

We also considered the question of whether the parallelism effect is symmetrical, i.e., independent of the type of target NP (relative clause or adjectival phrase), although the relevant comparisons have to be considered with caution, due to potential extraneous factors mentioned above. There was clearly symmetry in Experiment 1 for coordination, but Experiment 2 for subordination only found a parallelism effect when the NP2 was a relative clause. In the current experiment, we found that the effect is symmetrical for total time, but limited to relative clause NP2s in first pass and second pass, and to adjective phrase NP2s in regression path duration. Therefore, the current experiment extends Experiment 2 in that it provides some evidence for the symmetry of the effect.

Finally, we note that the results of the current experiment are compatible with the hypothesis about the role of frequency in parallelism that we outlined when discussing Experiment 1: if marked (i.e., infrequent) structures show a stronger parallelism effect, then we would expect to see a higher parallelism advantage in tough-constructions compared to unmarked relative clauses and adjective phrases. Informally this is confirmed: the parallelism effect is numerically larger in Experiment 1 when compared with the coordination condition of Experiment 3 (see Figures 2 and 4).

\footnotetext{
${ }^{8}$ The regression included crossed random intercepts for subject and item, and subject-specific random slopes for the NP2 factor.
} 


\section{General Discussion}

Experiment 1 demonstrated the basic parallelism preference for coordinated NPs. We used a fully crossed design that orthogonally manipulated the form of the first and the second noun phrase in coordination, which included either an adjective phrase or a relative clause tough-construction. The results show an interaction of the two factors (the structure of the NP1 and the structure of the NP2), which confirms the parallelism effect; a contrast analysis showed that there is a significant parallelism effect for both the adjective and the relative clause construction. Experiment 1 therefore replicates previous findings of parallelism in Noun Phrase coordination (Frazier et al., 2000; Apel et al., 2007), but using a syntactic alternation in which the truth-conditional semantics is kept (virtually) constant between the two forms. Thus, we can rule out semantic influences on the parallelism effect in NP coordination.

The aim of Experiment 2 was to examine whether the parallelism effect extends to noncoordination contexts. Like Experiment 1, this study crossed a manipulation of the structure of the NP1 and the NP2, but unlike Experiment 1, it only included subordinate clause structures. The materials used the alternation between simple adjective phrases and simple relative clauses, rather than tough-constructions as in Experiment 1. We obtained an interaction between the NP1 factor and the NP2 factor, supporting the existence of a parallelism effect in subordinated NPs. We also observed informally that the magnitude of the parallelism effect for NPs related by subordination was smaller than that observed for coordinate structures in Experiment 1. Furthermore, we saw that the effect is asymmetric; in total time and second pass, the parallelism speed-up was only present when the NP2 was a relative clause.

Experiment 3 investigated whether parallelism effects differ in magnitude in coordination and subordination constructions. Again, a fully crossed design (NP1 and NP2 as either adjective phrase or relative clause) was used, and this was combined with a manipulation of the syntactic environment (coordination and subordination). The results again yielded an interaction of NP1 and NP2, confirming the existence of a parallelism effect. In contrast analyses, we were able to show that the interaction holds for both coordination and subordination separately, and that it was detectable for both types of NP2 (though not in all eye-tracking measures). The experiment therefore replicated the subordination effect of Experiment 2, but also showed that the results for coordination in Experiment 1 hold for non-tough constructions as well.

Crucially, however, Experiment 3 failed to yield a significant three-way interaction of NP1, NP2, and Structure. Therefore, there is no reliable evidence that the parallelism effect differs in magnitude for coordination and subordination (even though the effect was numerically larger for coordination). Experiment 3 therefore does not provide support for the existence of a specialized mechanism that only applies to coordinate structures (Frazier et al., 2000; Apel et al., 2007). In contrast, our results are compatible with the view that parallelism is an instance of syntactic priming in comprehension, as proposed by Dubey et al. (2008). Priming effects apply to any form of structural repetition, and should therefore be found both in coordination and subordination. This view of parallelism as priming is also supported by corpus evidence: Dubey et al. (2008) demonstrate a parallelism effect for coordinated NPs in corpus data, but they also show that this effect generalizes to non-coordinated NPs.

It is important to note, however, that the parallelism effect for subordination was relatively small in Experiments 2 and 3, and that considerable statistical power (12 items per condition) was required in order to detect the effect. This may explain why previous authors such as Frazier et al. 
(2000) and Apel et al. (2007) reported null effects in studies that used between four and eight items per condition. In this context, it is also worth pointing out that most established syntactic priming results were obtained for production, rather than for comprehension. It has been observed that priming effects in comprehension appear to be weaker, or more difficult to obtain, than corresponding priming effects in production (Pickering \& Ferreira, 2008), in line with the findings in the present paper.

Apart from the relatively weak nature of priming effects in comprehension, it has also been hypothesized that comprehension priming may rely on lexical repetition between prime and target, while production priming can be detected whether or not open class lexical material is repeated. In a visual world eye-tracking study, Arai et al. (2007) presented ditransitive sentences auditorily while participants viewed a scene. They found a reliable priming effect in anticipatory eye-movements. Specifically, soon after hearing a ditransitive verb, such as give, people tended to look at the object that would be expected to mentioned in the first post-verbal argument. The looks to the objects were reliably affected by the syntactic form of a previously presented prime sentence, so that if the prime sentence used a prepositional object construction (e.g., The pirate will give the necklace to the princess), people tended to look at the referent of the expected direct object, while if the prime sentence used a double object construction (e.g., The pirate will give the princess the necklace), people tended to look at the referent of the expected indirect object. However, this effect was only obtained when the same verb was used in both prime and target. This led the authors to hypothesize that lexical repetition may be necessary for comprehension priming.

However, there are also results in the literature showing that lexical repetition is not always necessary for comprehension priming. This has been shown particularly in the literature on priming in garden paths. For example, in a series of self-paced reading studies, Branigan et al. (1995) found that the difficulty of recovering from misanalysis in syntactic garden path sentences can be reduced by the prior presentation of a structurally identical garden path prime, and similar results have recently been found by Traxler (2008) in an eye-tracking study. Importantly, in both studies, the priming effect was obtained without repeating content words between prime and target sentences. Moreover, Thothathiri and Snedeker (2008) report a series of visual world studies similar to that of Arai et al. (2007) (but using a different task) which also showed evidence of priming without lexical repetition.

If, as we suggest, the parallelism effect reported in the literature can be interpreted as syntactic priming, then these studies can also be seen as further evidence that priming effects in comprehension do not rely on lexical repetition. In most parallelism experiments, including those of Frazier et al. (2000) and Apel et al. (2007), as well as the studies reported here, open class lexical content was not repeated between the prime and the target NPs, and yet a reliable parallelism advantage was observed. It seems likely that lexical repetition may merely increases the strength of the priming effect (in analogy to the lexical boost in production priming, e.g., Pickering \& Branigan, 1998), thus making it easier to detect.

\section{Conclusions}

This paper has demonstrated reliable parallelism effects both inside and outside of the coordination environment. The results are compatible with a model in which the parallelism preference is an instance of structural priming. 


\section{References}

Apel, J., Knoeferle, P., \& Crocker, M. W. (2007). Processing parallel structure: Evidence from eye-tracking and a computational model. In S. Vosniadou, D. Kayser, \& A. Protopapas (Eds.), Proceedings of the European Cognitive Science Conference. Mahwah, NJ: Lawrence Erlbaum Associates.

Arai, M., Gompel, R. P. G. V., \& Scheepers, C. (2007). Priming ditransitive structures in comprehension. Cognitive Psychology, 54(3), 218-250.

Baayen, R. H. (2008). Analyzing linguistic data: A practical introduction to statistics using R. Cambridge: Cambridge University Press.

Baayen, R. H., Davidson, D. J., \& Bates, D. M. (2008). Mixed-effects modeling with crossed random effects for subjects and items. Journal of Memory and Language, 59(4), 390-412.

Bock, J. K. (1986). Syntactic persistence in language production. Cognitive Psychology, 18(3), 355-387.

Branigan, H. P., Pickering, M. J., \& Cleland, A. (2000). Syntactic coordination in dialogue. Cognition, 75(2), $13-25$.

Branigan, H. P., Pickering, M. J., Liversedge, S. P., Stewart, A. J., \& Urbach, T. P. (1995). Syntactic priming - investigating the mental representation of languge. Journal of Psycholinguistic Research, 24(6), 489-506.

Branigan, H. P., Pickering, M. J., \& McLean, J. F. (2005). Priming prepositional-phrase attachment during comprehension. Journal of Experimental Psychology: Learning, Memory and Cognition, 31(3), 468481.

Carlson, K. (2001). The effects of parallelism and prosody on the processing of gapping structures. Language and Speech, 44(1), 1-26.

Chomsky, N. (1957). Syntactic structures. The Hague: Mouton.

Cleland, A. A., \& Pickering, M. J. (2003). The use of lexical and syntactic information in language production: Evidence from the priming of noun-phrase structure. Journal of Memory and Language, 49(2), 214-230.

Dubey, A., Keller, F., \& Sturt, P. (2008). A probabilistic corpus-based model of syntactic parallelism. Cognition, 109(3), 326-344.

Frazier, L., Munn, A., \& Clifton, C. (2000). Processing coordinate structure. Journal of Psycholinguistic Research, 29(4), 343-368.

Frazier, L., Taft, L., Roeper, T., Clifton, C., \& Ehrlich, K. (1984). Parallel structure: A source of facilitation in sentence comprehension. Memory and Cognition, 12(5), 421-430.

Gibson, E. A. F. (1998). Linguistic complexity: Locality of syntactic dependencies. Cognition, 68(1), 1-76.

Gries, S. T. (2005). Syntactic priming: A corpus-based approach. Journal of Psycholinguistic Research, 34(4), 365-399.

Hale, J. (2001). A probabilistic Earley parser as a psycholinguistic model. In Proceedings of the 2nd Conference of the North American Chapter of the Association for Computational Linguistics (Vol. 2, pp. 159-166). Pittsburgh, PA: Association for Computational Linguistics.

Jaeger, T. F. (2008). Categorical data analysis: Away from ANOVAs (transformation or not) and towards logit mixed models. Journal of Memory and Language, 59(4), 434-446.

Knöferle, P., \& Crocker, M. (2006). Clause-level and constituent-level parallelism: eye-tracking coordinate structures in German. Talk at the 12th Conference on Architectures and Mechanisms for Language Processing, Edinburgh. Nijmegen, Netherlands.

Knöferle, P., \& Crocker, M. (2009). Constituent order and semantic parallelism in online comprehension: eye-tracking evidence from German. Quarterly Journal of Experimental Psychology, 62(12), 23382371.

Ledoux, K., Traxler, M. J., \& Swaab, T. Y. (2007). Syntactic priming in comprehension. Psychological Science, $18(2)$.

Pickering, M. J., \& Branigan, H. P. (1998). The representation of verbs: Evidence from syntactic priming in language production. Journal of Memory and Language, 39(4), 633-651. 
Pickering, M. J., \& Ferreira, V. (2008). Structural priming: A critical review. Psychological Bulletin, 134(3), $427-459$.

Rayner, K., \& Pollatsek, A. (1989). The psychology of reading. Englewood Cliffs, NJ: Prentice Hall.

Reitter, D., Hockenmaier, J., \& Keller, F. (2006). Priming effects in combinatory categorial grammar. In Proceedings of the Conference on Empirical Methods in Natural Language Processing (pp. 308-316). Sydney: Association for Computational Linguistics.

Reitter, D., Moore, J., \& Keller, F. (2006). Priming of syntactic rules in task-oriented dialogue and spontaneous conversation. In Proceedings of the 28th Annual Conference of the Cognitive Science Society (pp. 685-690). Mahwah, NJ: Lawrence Erlbaum Associates.

Scheepers, C. (2003). Syntactic priming of relative clause attachments: persistence of structural configuration in sentence production. Cognition, 89(3), 179-205.

Szmrecsanyi, B. (2005). Creatures of habit: A corpus-linguistic analysis of persistence in spoken English. Corpus Linguistics and Linguistic Theory, 1(1), 113-149.

Thothathiri, M., \& Snedeker, J. (2008). Give and take: syntactic priming during spoken language comprehension. Cognition, 108(1), 51-68.

Traxler, M. J. (2008). Lexically independent priming in online sentence comprehension. Psychonomic Bulletin and Review, 15(1), 149-155. 


\section{Appendix: Experimental Materials}

\section{Experiment 1}

Stimuli for Experiment 1 are given below in the condition NP1 = RelC, NP2 $=$ RelC. The other conditions can be reconstructed by re-arranging the internal structure of the relevant noun phrases. For example, for item 1, the NP1 = AdjP, NP2 = AdjP condition would be: A difficult to read book and a risky to cross street were mentioned by John's friend.

1. A book that was difficult to read and a street that was risky to cross were mentioned by John's friend.

2. A cake that was messy to eat and a key that was stiff to turn were on Frank's mind.

3. A rock that was dangerous to climb and a flower that was nice to behold were shown in Harry's book.

4. A mark that was distinct to see and a puzzle that was annoying to do had bothered Jenny.

5. A ticket that was easy to book and a price that was reasonable to pay had relieved Helen.

6. A sack that was heavy to lift and a song that was hard to remember were dogging Gerald.

7. A language that was good to learn and a dish that was easy to cook were recommended by Larry.

8. A noise that was scary to hear and a film that was exciting to watch were experienced by Jack.

9. A fact that was hard to describe and a sin that was painful to confess were troubling Jill.

10. A hamster that was irritating to keep and a stain that was tough to clean were making Henry complain.

11. A crossword that was simple to solve and a kite that was decent to fly were vaunted by Anna.

12. A fruit that was sour to taste and a toilet that was horrible to smell had made Paul feel sick.

13. A play that was tiresome to endure and a poem that was tricky to learn were boring Brian.

14. A game that was painless to play and a victory that was good to report had delighted Lucy.

15. A show that was wonderful to see and a castle that was lovely to visit were written about by Rachel.

16. A suit that was pricey to hire and a meeting that was harsh to follow were criticised by Wendy.

17. A lecture that was clear to understand and a carol that was pretty to sing were noted by Thomas.

18. A glass that was awkward to use and a wine that was gorgeous to drink were described by Nancy.

19. A bicycle that was comfy to ride and a laptop that was light to carry were bought by Geoffrey.

20. A car that was impossible to drive and a trolley that was tiring to push were sold by Hubert.

21. A blanket that was soft to touch and a sausage that was safe to eat were described by Kerry.

22. A story that was depressing to tell and an event that was nasty to remember were seen by Maria.

23. A quiz that was challenging to try and a problem that was simple to grasp were solved by Bill.

24. An accident that was shocking to recall and a drug that was quick to take were noted by Natasha.

\section{Experiment 2}

The stimuli for Experiment 2 are given in the condition NP1 = RelC, NP2 = RelC. The other conditions can be reconstructed by re-arranging the internal structure of the relevant noun phrases. For example, for item 1, the NP1 = AdjP, NP2 = AdjP condition would be: A gruelling article argued that a risky street should best be avoided.

1. An article that was gruelling argued that a street that was risky should best be avoided.

2. A recipe that was easy showed that a cake that was delicious can be cooked even by a beginner. 
3. A cliff that was dangerous meant that a flower that was beautiful could not be reached.

4. A note that was conspicuous indicated that a puzzle that was annoying had been spotted by James.

5. A ticket that was cheap promised that a price that was reasonable would be available for the show.

6. A sack that was heavy meant that a job that was tough would irritate Gerald.

7. A book that was helpful claimed that a language that was useful might help John's career.

8. A review that was unkind concluded that a film that was scary should best be avoided.

9. A letter that was incomprehensible said that a sin that was painful might bother Jill.

10. A hamster that was irritating meant that a stain that was tough would have to be removed.

11. A conflict that was resolvable promised that a war that was treacherous would be the main focus.

12. A toilet that was smelly meant that a fruit that was sour made Paul feel sick.

13. A homework that was tedious specified that a poem that was tricky had to be finished by Monday.

14. A game that was painless showed that a victory that was good could delight Lucy.

15. A sign that was obscured said that a castle that was lovely could be found nearby.

16. A meeting that was harsh criticised that a suit that was pricey would be part of the deal.

17. A sermon that was clear claimed that a carol that was pretty would make Christmas worthwhile.

18. A glass that was awkward meant that a wine that was gorgeous could not be enjoyed fully.

19. A manual that was good stated that a laptop that was light will self-destruct tomorrow.

20. A map that was confusing showed that a village that was nearby had been missed.

21. A restaurant that was expensive claimed that a sausage that was healthy may change Pete's life.

22. A story that was depressing indicated that an event that was nasty would bother Maria.

23. A quiz that was challenging proved that a problem that was simple could be solved by Bill.

24. An accident that was shocking indicated that a drug that was bitter might not be safe.

25. A landlord who was sleazy said that a tenant who was honest should be moving in fairly soon.

26. A teacher who was excellent said that a pupil who was good had been working very hard.

27. A girl who was young said that a stranger who was weird had been seen in the street.

28. A boy who was funny said that a cat who was fluffy had been sleeping on the sofa.

29. A woman who was blond said that a jeweller who was wealthy had been injured by the robber.

30. An owner who was proud said that a dog who was large loved to go for walks in the park.

31. A swimmer who was fast said that a runner who was slow competed a few times in the Olympics.

32. A cleaner who was grouchy said that a student who was messy had never cleaned his bathroom.

33. A boss who was demanding said that a worker who was lazy did not do the job properly.

34. A director who was happy said that an actor who was talented had put on a superb show.

35. A mother who was stern said that a child who was rowdy had been causing trouble all day long.

36. A grandmother who was gentle said that a grandfather who was grouchy ate some biscuits with a cup of tea.

37. A pedestrian who was quiet said that a man who was homeless had been walking on the street.

38. A doctor who was busy said that a nurse who was caring found the medicine in the cabinet.

39. A butcher who was charming said that a baker who was stingy had been robbed whilst on holiday.

40. A cyclist who was angry said that a trucker who was friendly had strange political views.

41. A physicist who was sad said that a biologist who was happy had won the singing contest.

42. A zookeeper who was pretty said that a monkey who was shy had been afraid of children.

43. A pirate who was witty said that a dolphin who was graceful had been swimming around the ship.

44. A policeman who was foolish said that a prisoner who was clever would return from the shops later.

45. A bouncer who was angry said that a man who was drunken could be a recipe for trouble. 
46. A man who was injured said that a boy who was vulgar could have been involved in the fight. 47. A lawyer who was rich said that a businessman who was greedy seemed to be acting suspiciously. 48. A shopkeeper who was careless said that an accountant who was boring had been trying to work out some figures.

\section{Experiment 3}

The 48 new stimuli for Experiment 3 are given in the condition NP1 = RelC, NP2 = RelC, Struc $=$ Subord. The other conditions can be reconstructed by re-arranging the internal structure of the relevant noun phrases, as for Experiment 2. The coordination condition can be reconstructed by replacing said that (and analagous subordinating material) with and. The remaining 48 stimuli of Experiment 3 were identical to the stimuli of Experiment 2 listed above, except for item 32, in which student was replaced by occupant and item 45, in which angry was replaced by wrathful, to avoid lexical repetition across items.

1. A librarian who was strict said that a patron who was loud caused a ruckus in the fiction section.

2. A fisherman who was smelly knew that a crewman who was inexperienced had ripped the fishing net.

3. A soldier who was strong observed that a sailor who was wimpy fought in the bar.

4. A hairdresser who was talkative said that a client who was recent didn't like watching TV.

5. A babysitter who was nasty said that a baby who was shrieking had kept the neighbours up all night.

6. An engineer who was geeky explained that a workman who was brawny had not followed instructions.

7. A volunteer who was helpful said that a pensioner who was needy had been living in the church.

8. A barmaid who was attractive said that a punter who was insistent had been making sexual innuendoes.

9. A joiner who was thin noted that a plumber who was fat had decided to join the gym.

10. A contestant who was daft said that a judge who was wry had made a series of witty comments.

11. A juvenile who was delinquent said that a cop who was angry had been involved in a quarrel.

12. A candidate who was bitter knew that a manager who was mean had made the interview uncomfortable.

13. A bachelor who was sexy found that a lady who was amusing had been among the interesting dinner guests.

14. A commando who was muscular said that a terrorist who was nervous had been involved in a covert operation.

15. A veteran who was old claimed that a recruit who was new had been a disgrace to the military.

16. A publisher who was thrify said that an author who was famous had been overpaid.

17. A critic who was miserable stated that an artist who was conceptual had not offered anything new.

18. A coach who was supportive held that a goalie who was fearless had been a good addition for the team.

19. A student who was eager read that a professor who was crazy went to the graduation ceremony.

20. An actor who was penniless worried that a writer who was infamous missed the movie premiere.

21. A medic who was inexperienced claimed that an addict who was hallucinating had eaten lunch in the canteen. 
22. An instructor who was short thought that an athlete who was tall was getting bored with the training programme.

23. A tourist who was annoying denied that a visitor who was noisy had finally left the museum.

24. A knight who was brave warned that a princess who was fair had been eaten by the dragon.

25. A toddler who was tired whined that a mother who was exhausted had gone to bed early.

26. A criminal who was sinister swore that a witness who was cooperative would pay a heavy price.

27. A driver who was foolhardy shouted that a cyclist who was slow had better move out of the way.

28. A grandfather who was wary sighed that a grandchild who was bored had been watching TV all day.

29. A boss who was new wished that an assistant who was eager had gone out for a drink after work.

30. An employee who was ignorant stated that a manager who was lazy had not been paid for months.

31. A businessman who was ambitious said that a diplomat who was Jamaican had been due to attend the meeting.

32. A king who was powerful said that a servant who was cheerful had been enjoying the national festivities.

33. A director who was successful said that an actress who was famous could be seen at the restaurant.

34. A tourist who was confused said that a driver who was irate had been making some complaints.

35. A doctor who was gentle said that a patient who was elderly had spent a long time in the consulting room.

36. A butcher who was furious said that a customer who was rude had been annoying people in the shop.

37. A schoolgirl who was serious said that a dancer who was skillful seemed to be working very hard.

38. A biologist who was overweight said that a gorilla who was proud had become famous in the zoo.

39. A journalist who was curious said that a politician who was corrupt had been hanging around outside the club.

40. A shopkeeper who was hardworking believed that a cleaner who was absent would be at the shop early in the morning.

41. A nurse who was tender stated that a victim who was upset had been feeling quite stressed out.

42. A rock-star who was rich claimed that an actress who was tall had been spotted entering the hotel room.

43. A footballer who was Brazilian revealed that a millionaire who was successful had been extremely lucky in the stock market.

44. A scientist who was crazy thought that a spy who was British had been brainwashed by North Korean agents.

45. A gangster who was stupid denied that a criminal who was clever had been sent to prison.

46. A priest who was devout found that a curate who was depressed would be joining a new parish.

47. An engineer who was experienced knew that a graduate who was brilliant would be needed for the job.

48. A servant who was unlucky hoped that a maid who was buxom would join the staff of the house. 